\title{
Modulation of Early Olfactory Processing by an Octopaminergic Reinforcement Pathway in the Honeybee
}

\author{
Tahira Farooqui, ${ }^{1}$ Kellie Robinson, ${ }^{2}$ Harald Vaessin, ${ }^{3}$ and Brian H. Smith ${ }^{1}$ \\ Departments of ${ }^{1}$ Entomology, ${ }^{2}$ Molecular, Cellular, and Developmental Biology, and ${ }^{3}$ Molecular Genetics and Center for Molecular Neurobiology, The Ohio \\ State University, Columbus, Ohio 43210
}

\begin{abstract}
Processing of olfactory information in the antennal lobes of insects and olfactory bulbs of vertebrates is modulated by centrifugal inputs that represent reinforcing events. Octopamine release by one such pathway in the honeybee antennal lobe modulates olfactory processing in relation to nectar (sucrose) reinforcement. To test more specifically what role octopamine plays in the antennal lobe, we used two treatments to disrupt an octopamine receptor from Apis mellifera brain (AmOAR) function: (1) an OAR antagonist, mianserin, was used to block receptor function, and (2) AmOAR double-stranded RNA was used to silence receptor expression. Both treatments inhibited olfactory acquisition and recall, but they did not disrupt odor discrimination. These results suggest that octopamine mediates consolidation of a component of olfactory memory at this early processing stage in the antennal lobe. Furthermore, after consolidation, octopamine release becomes essential for recall, which suggests that the modulatory circuits become incorporated as essential components of neural representations that activate odor memory.
\end{abstract}

Key words: antennal lobe; octopamine neurotransmission; AmOAR; RNAi; proboscis extension reflex; olfactory memory consolidation; VUMmx1; Apis mellifera

\section{Introduction}

Neural bases for memory are typically distributed across several areas of the brain (Milner et al., 1998), and different areas may be involved in acquisition, consolidation, and retrieval of memory (Dubnau et al., 2001; McGuire et al., 2001). This typically includes areas that receive primary sensory afferents. Components of neural plasticity toward odors occur in the antennal lobes (ALs) of insects (Faber et al., 1999; Stopfer and Laurent, 1999) and olfactory bulbs (OBs) of mammals (Wilson et al., 1985; Sullivan and Dryer, 1996; Yuan et al., 2002), which directly process sensory information from olfactory epithelia (Hildebrand and Shepherd, 1997). Coactivation of olfactory sensory pathways with reinforcement pathways from other sensory modalities changes synaptic processing to affect neural representations of odor in the AL and $\mathrm{OB}$. Experience with odors during birth and mating as adults (Kendrick et al., 1992, 1997) and during suckling as neonates (Wilson and Sullivan, 1994) modifies physiological responses of mitral cells in the OB quantitatively. Experience can also change receptive fields of mitral cells (Fletcher and Wilson, 2002). Recently, evidence has also indicated nonassociative and associative modification of spatial (Faber et al., 1999) and temporal (Stopfer and Laurent, 1999) activation patterns of cell ensembles in the AL.

These data suggest that neural representations of the condi-

Received Jan. 31, 2003; revised March 27, 2003; accepted April 8, 2003.

This work was supported by National Institutes of Health Grant 9-R01-RR-14166 to B.H.S. from the National Center for Research Resources and by an award from the National Science Foundation to H.V. We thank Dr. R. Davis (Baylor College of Medicine, Houston, TX) and Dr. Kyung-An Han (Department of Biobehavioral Health and The Life Sciences Consortium/Neuroscience, Pennsylvania State University, University Park, PA) for providing essential clones and OAMB antiserum for the study. We also thank Shweta Chandra for providing Drosophila CDNA clone, Geraldine Wright for assistance with the PER assay, and Julie Mustard for her critical reading of this manuscript.

Correspondence should be addressed to Dr. Brian H. Smith, Department of Entomology, The Ohio State University, 103 Jennings Hall, 1735 Neil Avenue, Columbus, OH 43210-1220. E-mail: smith.210@osu.edu.

Copyright $\odot 2003$ Society for Neuroscience $\quad$ 0270-6474/03/235370-11\$15.00/0 tioned stimulus (CS; odor) and reinforcement (unconditioned stimulus; US) converge at this early level of processing of sensory information in the AL and OB (Wilson and Sullivan, 1994). An important issue, therefore, is how other sensory pathways represent reinforcement in these neuropils. In mammals, a number of pathways from more central brain regions provide centrifugal inputs into the OB (Shipley and Ennis, 1996). One such pathway releases norepinephrine and is necessary for the development of learned odor preferences in sheep and rats (Pissonnier et al., 1985; Sullivan et al., 1989; Levy et al., 1990). Norepinephrine interacts with serotonin receptors to mediate a consolidation of a component of olfactory memory in the OB (Yuan et al., 2003). Biogenic amines have also been implicated in plasticity in the AL. Release of serotonin by an interneuron that arborizes throughout the moth AL broadens action potentials in projection neurons (Dolzer et al., 2001). An identified ventral unpaired medial (VUMmx1) cell in the honeybee brain mediates an interaction between sucrose-sensitive taste receptors in the US pathway and olfactory sensory afferents in the CS pathway of the AL (Hammer, 1993). VUM releases octopamine (OA) into all or most glomeruli of the $\mathrm{AL}$, and its responsiveness to odor changes in a way correlated with associative changes in the behavioral response to odor in the conditioning paradigm (Hammer, 1993).

Our objective was to evaluate the role that $\mathrm{OA}$ release in the AL plays in behavioral olfactory conditioning in the honeybee (Erber et al., 1993). OA has been implicated in memory consolidation in several brain regions, including the AL (Hammer and Menzel, 1998). If OA release in the AL is an essential component of a distributed olfactory memory in the honeybee brain, then interference with OA receptor (OAR) function should produce a decrement in conditioned response to odors. We therefore used pharmacological and molecular approaches to block or disrupt AmOAR and subsequent activation-suppression of downstream 
second messenger pathways (Hildebrandt and Müller, 1995; Blenau and Baumann, 2001). For both approaches, we used proboscis extension reflex (PER) conditioning, which has been used widely to study behavioral and physiological mechanisms of olfactory learning (Bitterman et al., 1983; Menzel, 1985, 1990). We report that impairment of AmOAR significantly reduces acquisition and conditioned responding to odor. The most surprising finding, perhaps, is that it can impair recall independent of acquisition, which suggests that the octopamine pathway represented by VUM becomes an integral part of the neural representation of odor memory.

\section{Materials and Methods}

Subjects. Honeybees (Apis mellifera) used for this study were from a genetically closed breeding population maintained at the Rothenbuhler Honeybee Research Laboratory at The Ohio State University.

PER conditioning. PER conditioning was used to assay responses to odors (Menzel and Bitterman, 1983; Hosler et al., 2000). Briefly, worker honeybees were collected from an indoor flight room maintained at 25 $30^{\circ} \mathrm{C}$ and on a $16 / 8 \mathrm{hr}$ light/dark cycle. Subjects were collected individually in glass vials 3-4 hr before surgery and briefly cooled in an ice-water bath until they ceased moving. They were then placed into restraining harnesses that allowed the free movement of antennas and mouthparts. To restrict any movement of the head during surgery, each subject's head was immobilized by allowing molten dental wax to flow into and harden the space between the head and the harness. A small window was cut in the head capsule just above the antennas to expose the AL. After this surgery, each subject was fed with $0.4 \mu \mathrm{l}$ droplet of $1.25 \mathrm{M}$ sucrose solution and was left undisturbed for at least $1 \mathrm{hr}$.

The detailed conditioning protocol has been described previously (Smith, 1997; Stopfer et al., 1997; Hosler et al., 2000). Briefly, a subject is individually moved to a conditioning arena through which air is continuously drawn into an exhaust system. At $\sim 30 \mathrm{sec}$ after placement, odorladen air is injected for $4 \mathrm{sec}$ into the exhaust stream that is drawn over the subject's antennas. Three seconds after odor onset, the subject's antennas were stimulated with a $0.4 \mu \mathrm{l}$ droplet of $1.25 \mathrm{M}$ sucrose solution. This elicited extension of the mouthparts, after which the subject was allowed to consume the entire droplet. All subjects received six such acquisition trials with the conditioned odor $(\mathrm{C})$.

Acquisition trials were separated by a $30 \mathrm{sec}$ intertrial interval to minimize the probability that the pretreated drug would wear off during acquisition. Six acquisition trials lasted $\sim 3$ min. Massed trials such as these are not optimal to produce maximal rates of conditioning performance (Menzel et al., 2001), which is reflected in the rates of conditioning we report below. But our CS-US pairing controls have indicated that conditioned responding in our training protocol arises from associative conditioning (Robinson, 1999). During each trial, a subject was scored as having exhibited a positive response if it extended its proboscis after the onset of odor but before presentation of the sucrose. Recall tests were performed with odors C, molecularly similar (S), and molecularly dissimilar (D) presented at 3 min intervals in randomized order across subjects and without sucrose reinforcement. Test trials were performed 90 or $100 \mathrm{~min}$ (see Fig. 1a,b.1) or $26 \mathrm{hr}$ after conditioning (see Fig. 1b.2), depending on the experiment. All statistical analyses were based on oneor two-way ANOVA, followed where appropriate by least significant difference tests for differences among groups (Sokal and Rohlf, 1981).

Pharmacological analysis. Degen et al. (2000) evaluated several antagonists to block neuronal octopamine receptors in the honeybee and locust and showed that mianserin (MAS; Sigma, St. Louis, MO) had the highest affinity with $K_{\mathrm{i}}$ values of 0.73 and $1.2 \mathrm{~nm}$, respectively. Therefore, we chose MAS for pharmacological analysis and applied a $4 \mathrm{nl}$ droplet of either saline (in mM: $\mathrm{NaCl} 135, \mathrm{KCl} 5.3, \mathrm{CaCl}_{2} 1.36$, sucrose 8.47, Trizma$\mathrm{HCl} 50$, at a $\mathrm{pH}$ of 7.0) or $4 \mathrm{nl}$ of saline containing MAS at either 20, 200, or $2000 \mu \mathrm{M}$ concentrations in each AL. Treatments were applied $10 \mathrm{~min}$ before conditioning and 10 min before testing (see Fig. 1a). One-way ANOVA was used for across-group comparison of acquisition responses. Recall responses were analyzed by two-way ANOVA.

Isolation of AmOAR. AmOAR cDNA was isolated from a honeybee head cDNA library (Stratagene, La Jolla, CA; Wallace and Smith, unpublished) with a Drosophila melanogaster DAMB clone (kindly provided by Ron Davis, Baylor College of Medicine, Houston, TX) using lowstringency hybridization according to Knust et al. (1987). In this screen, a single cDNA clone was recovered and sequenced.

A PCR-generated fragment of AmOAR cDNA (417 nucleotides) was cloned into the dual promoter vector (pCR II) using a TA cloning kit (Invitrogen, San Diego, CA). Transformation was done into INV $\alpha \mathrm{F}^{\prime}$, Escherichia coli one-shot competent cells, and plasmid DNA was purified with a QIAGen purification kit (Qiagen, Valencia, CA). DNA sequencing was performed at the DNA Sequencing Facility at The Ohio State University (Columbus, $\mathrm{OH}$ ). Pairwise sequence similarity with known protein sequences was determined with the BLAST-X alignment tool computed at the National Center of Biotechnology Information (NCBI) (Altschul et al., 1997). Multiple sequence alignment of proteins was performed with ClustalW (Thompson et al., 1994). Percentage identity in residue overlap was determined by the LALNVIEW program at the ExPASy molecular biology server.

Double-stranded RNA-mediated genetic interference. A PCR-template method of Kennerdell and Carthew (1998) was used to synthesize double-stranded RNA (dsRNA). Briefly, forward and reverse primer sequences that allow amplification of the region of interest for AmOAR dsRNA were selected from the AmOAR nucleotide sequence (positions 1-252 in Fig. 4a). To facilitate the direct transcription of RNA from the PCR product, the T7-promoter sequence (TAATACGACTCACTATAGGGAGACCAC) was attached to the $5^{\prime}$ end of each primer sequence. A $50 \mu \mathrm{l}$ PCR was performed with $100 \mathrm{ng}$ of recombinant plasmid DNA template, 25 pmol of each T7-linked primer, $8 \mathrm{~mm} \mathrm{MgCl}_{2}, 0.5 \mathrm{~mm}$ of each dNTP, and $2.5 \mathrm{U}$ Taq DNA polymerase. The DNA was amplified by 35 cycles of $1 \mathrm{~min}$ at $94^{\circ} \mathrm{C}, 1 \mathrm{~min}$ at $58^{\circ} \mathrm{C}$, and $1 \mathrm{~min}$ at $72^{\circ} \mathrm{C}$ followed by an additional extension for $10 \mathrm{~min}$ at $72^{\circ} \mathrm{C}$. PCR product was loaded on $1.5 \%$ agarose gel. The DNA fragment was excised from the agarose gel and purified by the QIAquick Gel Extraction Kit protocol (Qiagen). After purification, the PCR product was used in an in vitro transcription reaction using MAXIscript kit (Ambion, Austin, TX). The $20 \mu$ l transcription reaction was performed with $1 \mu \mathrm{g}$ DNA template, $0.5 \mathrm{~mm}$ NTPs, and 10 U T7 RNA polymerase at $37^{\circ} \mathrm{C}$ for $1 \mathrm{hr}$. After phenol-chloroform extraction, dsRNA was precipitated with $\mathrm{NH}_{4} \mathrm{OAc}-\mathrm{EtOH}$, and the pellet was resuspended in injection buffer containing $5 \mathrm{~mm} \mathrm{KCl,} 10 \mathrm{mM} \mathrm{NaH}_{2} \mathrm{PO}_{4}$, at a $\mathrm{pH}$ of 7.8 (Spradling, 1986).

Two protocols were used to evaluate RNA-mediated interference (RNAi) (see Fig. 1b.1,b.2). In the protocol shown in Figure 1b.1, $4 \mathrm{nl}$ of injection buffer (Spradling, 1986) or $4 \mathrm{nl}$ of injection buffer containing AmOAR dsRNA (500 pg) was injected into each AL $2 \mathrm{hr}$ after surgery. Bees were left undisturbed for $24 \mathrm{hr}$ at room temperature in a humidified box. The next day they were conditioned with odor C. Ninety minutes later, they were tested with odors C, S, and D. In the protocol shown in Figure 1b.2, $2 \mathrm{hr}$ after surgery, honeybees were conditioned with odor C. Two hours later, injection buffer or injection buffer containing AmOAR dsRNA was injected into each AL. Bees were left undisturbed for $24 \mathrm{hr}$ at room temperature under humidity and then tested with odors $\mathrm{C}, \mathrm{S}$, and D for recall response.

Western blot analysis. A 15 a peptide, DFRFAFKSIICKCFC, selected from the intracellular domain of AmOAR sequence was synthesized, and anti-peptide antiserum was raised in rabbits by Alpha Diagnostic International (San Antonio, TX). Control and $24 \mathrm{hr}$ post dsRNA-injected ALs were dissected from honeybee brains for each group and homogenized in Laemmli buffer (Laemmli, 1970). Samples were boiled for $10 \mathrm{~min}$. Homogenates were centrifuged at $4^{\circ} \mathrm{C}$ at $6000 \times g$ for $15 \mathrm{~min}$. Pellets were discarded and the supernatants saved and stored at $-20^{\circ} \mathrm{C}$. Proteins were separated by SDS-PAGE using a $7.5 \%$ SDS-PAGE resolving gel in a mini-V 8-10 vertical gel electrophoresis apparatus (Invitrogen, Grand Island, NY). Proteins were transferred to nitrocellulose membranes (BioRad, Hercules, CA) in a mini-V 8-10 electrophoretic blotter (Invitrogen) using 100-130 mA current for $2 \mathrm{hr}$. Nitrocellulose membranes were then blocked with $5 \%$ bovine serum albumin (BSA; Sigma) in Tris-buffered saline (TBS; $10 \mathrm{~mm}$ Tris, $150 \mathrm{~mm} \mathrm{NaCl}, \mathrm{pH}$ 8.0) for $2 \mathrm{hr}$ at room temperature. Membranes were then probed for $1 \mathrm{hr}$ at room temperature with polyclonal anti-peptide antiserum (anti-AmOAR; Alpha Diagnostic) at 
1:500 dilution in $0.2 \%$ Tween-TBS (TTBS) plus $5 \%$ BSA. Membranes were washed three times with TTBS, followed by incubation with secondary antibody horseradish peroxidase (HRP)-conjugated goat anti-rabbit IgG (Amersham Pharmacia Biotech, Piscataway, NJ) for 1 hr at room temperature at 1:15,000 dilution in TTBS plus 5\% BSA. Protein bands were visualized by an enhanced chemiluminescence detection system (ECL; Amersham Pharmacia Biotech).

In a parallel experiment to evaluate the specificity of the protein band for anti-AmOAR antiserum, the homogenates from control ALs were loaded on $7.5 \%$ SDS-PAGE resolving gel. After transfer, one-half of the nitrocellulose membrane was probed with anti-AmOAR antiserum at 1:500 dilution in TTBS plus 5\% BSA, and the second half was probed with antiAmOAR antiserum preadsorbed with the corresponding peptide $(100 \mu \mathrm{g} / \mathrm{ml})$ for $1 \mathrm{hr}$ at room temperature. Membranes were washed with TTBS and incubated for $1 \mathrm{hr}$ with HRPconjugated goat anti-rabbit IgG (Amersham) followed by ECL detection system as used above. To determine that an equal amount of protein was loaded in each lane, membranes were stripped and reprobed with an antibody to horseradish peroxidase (Jan and Jan, 1982). Polyclonal anti-HRP (Jackson ImmunoResearch Laboratories, West Grove, PA) was used at 1:3000 dilution in TTBS plus 5\% BSA overnight at $4^{\circ} \mathrm{C}$. After excessive washing with TTBS, membranes were incubated for $1 \mathrm{hr}$ at room temperature with HRP-conjugated goat anti-rabbit IgG (Amersham) and developed with ECL. Relative intensities of the protein bands were quantified by Quantity 1 software, version 4 (Bio-Rad).

\section{Results \\ MAS interferes with acquisition and recall processes}

In an initial experiment, we evaluated three concentrations of MAS to determine the most effective dose. We used a dual-injection protocol during which $4 \mathrm{nl}$ of saline with or without MAS was injected into each AL 10 min before conditioning and $10 \mathrm{~min}$ before testing recall (Fig. 1a). The level of acquisition differed among the four dosage treatment groups (Fig. $2 a)\left(F_{(3,187)}=17.4 ; p<0.0001\right)$. The control group and $20 \mu \mathrm{M}$ MAS-treated group showed almost the same rate of acquisition ( $\sim 65-70 \%$ of the subjects responded by the fourth trial), with only a slight, nonsignificant decrement evident in the MAS group. The acquisition curves of 200 and 2000 $\mu \mathrm{M}$ MAS-treated groups were not significantly different from each other, but both curves were significantly lower than control ( $p<0.05$; least significant difference test). At least $50 \%$ of the acquisition response was inhibited after the fourth trial with 200 and $2000 \mu \mathrm{M}$ MAS, which suggests that MAS interferes with acquisition.

We also investigated the effect of different concentrations of MAS on recall (Fig. 2b). We recorded the percentage of subjects in the control and MAS-treated groups that responded to the conditioned odor (C; 1-octanol). We also recorded the percentage that generalized the conditioned response to a structurally similar odor (S; 1-hexanol) and a structurally dissimilar odor (D; geraniol). The response to the conditioned odor $\mathrm{C}$ in the control group did not differ significantly from the $20 \mu \mathrm{M}$ MAS-treated group $\left(\chi^{2}=0.23 ; p=0.63 ; p=\mathrm{NS}\right)$. But, as during acquisition, the response to the conditioned odor in the control group was significantly lower in the $200 \mu \mathrm{M}$ MAS group $\left(\chi^{2}=5.26 ; p<\right.$ $0.02)$ and the $2000 \mu \mathrm{M}$ MAS group $\left(\chi^{2}=6.73 ; p<0.009\right)$. Therefore, MAS also interferes with recall, either through interference with acquisition or by blocking the response (see below).

We also compared responses within treatment groups but across the three odors C, S, and D. Subjects that received saline treatment to both ALs responded significantly more to $\mathrm{C}$ than to $S$ and to $\mathrm{D}\left(\chi^{2}=6.08 ; p<0.04\right)$, which is consistent with observations reported in our previous studies (Stopfer et al., 1997). Two-way ANOVA revealed a significant effect of treatment $(F=$ 5.2; $p<0.002$ ), which reflected an overall decrease in response across dosage. There was also a significant effect of test odor $(F=$ 8.6; $p<0.0001$ ), which reflected the decrease in response from $C$ to $S$ and D. But the interaction of treatment and test odor was not significant $(F=0.3 ; p=\mathrm{NS})$, which indicates that discriminability of the odors was unaffected by the treatment. These data therefore suggest that MAS interferes with acquisition but does not 

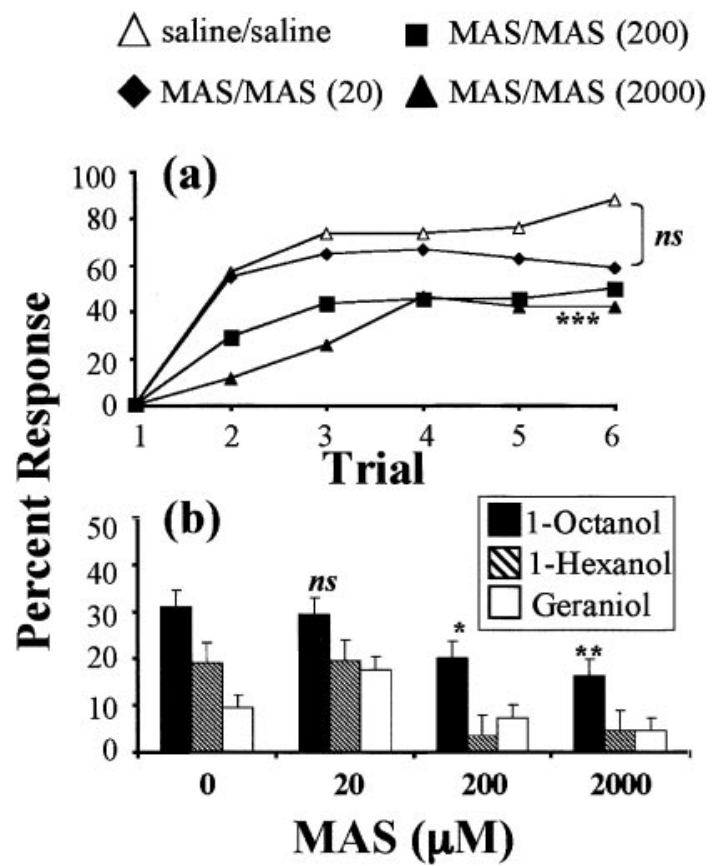

Figure 2. The effect of MAS dose on acquisition and/or recall testing. $a$, Acquisition to the conditioned odor (C: 1-octanol). Four nanoliters of saline-MAS solution $(20,200$, or $2000 \mu \mathrm{m})$ was injected into each AL 10 min before conditioning. Subjects were conditioned as in Figure $1 a$. $b$, Ninety minutes after conditioning, $4 \mathrm{nl}$ of saline-MAS was injected again in each AL, and 10 min later, subjects were tested with odors 1-octanol (C), 1-hexanol (S), and geraniol (D) in a randomized manner. Sample size: saline $(n=42), \operatorname{MAS} 20 \mu \mathrm{M}(n=51), \operatorname{MAS} 200 \mu \mathrm{m}(n=$ 55), MAS $2000 \mu \mathrm{M}(n=43)$. Asterisks indicate significant differences of respective points from control group $\left({ }^{*} p<0.05 ;{ }^{* *} p<0.005 ;{ }^{* * *} p<0.0001\right)$. ns, Not significantly different from control group.

impair discrimination, because with all three doses of MAS tested, the response was higher to $\mathrm{C}$ than to $\mathrm{S}$ or $\mathrm{D}$.

MAS did not impair the unconditioned response to the sucrose (US). Subjects treated with saline or MAS $(200 \mu \mathrm{M})$ were fed successive $2.0 \mu \mathrm{l}$ droplets of $1.5 \mathrm{M}$ sucrose solution until they were satiated, which was registered by a failure to extend the proboscis after application of sucrose solution to taste receptors on the antennas. Initially, all subjects in each group responded with proboscis extension to sucrose. Over successive feedings, subjects in the two treatment groups consumed statistically equal amounts of sucrose solution $(t=0.3 ; \mathrm{df}=32 ; p=\mathrm{NS})$. Subjects treated with saline $(n=16)$ consumed an average of $29.1 \mu \mathrm{l}$ (SEM, 7.5), and subjects treated with MAS $(n=18)$ consumed $28.0 \mu \mathrm{l}$ (SEM, 6.8).

MAS independently impairs olfactory acquisition and recall To determine whether the effect of $200 \mu \mathrm{M}$ MAS was on acquisition or on recall, we evaluated conditioning in groups that received different injection combinations: saline-saline, salineMAS, MAS-saline, and MAS-MAS (Fig. 1a). In the control group, in which saline was injected to the AL 10 min before conditioning and $10 \mathrm{~min}$ before recall testing, $75-80 \%$ of the subjects responded to conditioned odor by the fifth and sixth trials (Fig. 3a). The response of the saline-MAS treatment group, in which the acquisition conditions were identical to that of the control, was not significantly different from the control group $\left(F_{(1,89)}=0.04 ; p=\mathrm{NS}\right)$. Response levels were significantly lower than the control in the two groups treated with MAS during acquisition (MAS-saline: $F_{(1,96)}=25.06, p<0.0001$; MAS-MAS: $\left.F_{(1,96)}=18.76, p<0.0001\right)$. As in Figure $2 a$, these results also suggest that MAS interferes with the learning process.

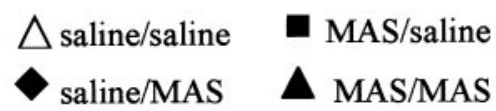

(a)
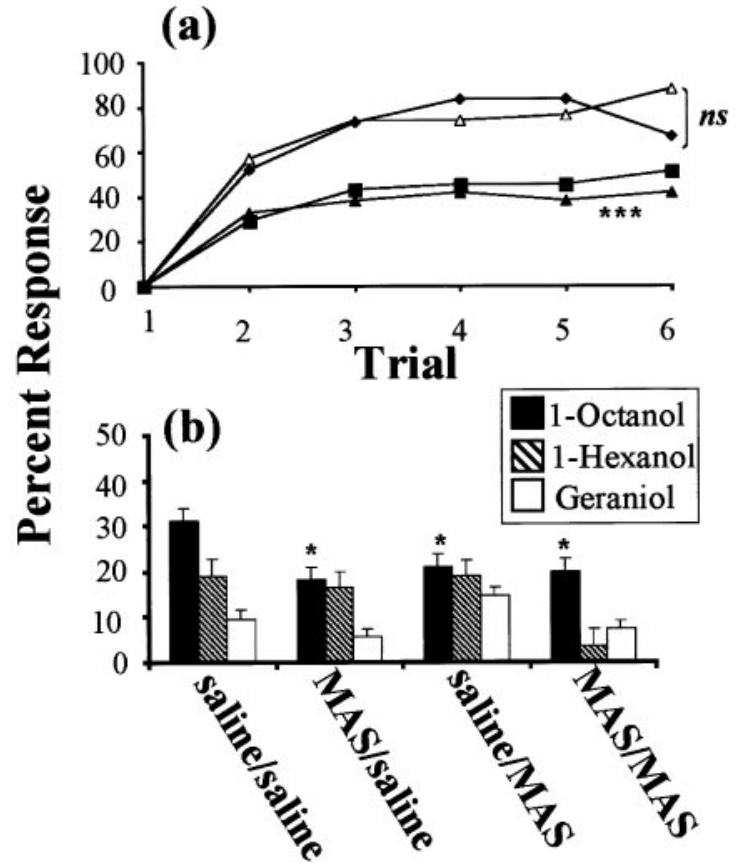

Figure 3. The effect of injection combination on acquisition and/or recall testing. a, Acquisition to conditioned odor (1-octanol). Subjects received a single application of saline or salineMAS. Ten minutes later, subjects were conditioned as in Figure $1 a . b$, Ninety minutes after conditioning, $4 \mathrm{nl}$ of saline or saline-MAS was applied again in each AL, followed by the $C$, $S$, and D test procedure. Sample size: saline-saline $(n=42)$, MAS-saline $(n=55)$, saline-MAS $(n=$ 48), MAS-MAS $(n=55)$. Asterisks indicate significant differences of respective points from control group $\left({ }^{*} p<0.05,{ }^{* * *} p<0.0001\right)$. ns, Not significantly different from control group.

Figure $3 b$ shows the effect of the injection combination on recall. As in Figure $2 b$, we recorded the percentage of subjects in the control and drug treatment groups that responded to odors $\mathrm{C}, \mathrm{S}$, and D. We found that all MAS combination groups show an $\sim 33 \%$ decrease in response to the conditioned odor (C) compared with the control group $\left(\chi^{2}=5.26 ; p<0.02\right)$. Because this is also true of the saline-MAS group, in which MAS was active only during the recall tests, it suggests that MAS interferes with recall. The comparison within the saline-saline group across the three odors C, S, and D showed a characteristic generalization gradient from odor $\mathrm{C}$ to $\mathrm{S}$ and $\mathrm{D}$ (Stopfer et al., 1997), as shown in Figure $3 b\left(\chi^{2}=6.25 ; p<0.04\right)$. As in Figure $2 b$, a two-way ANOVA revealed significant effects of drug treatment condition $(F=3.3 ; p<0.05)$ and test odor $(F=1.3 ; p<0.01)$. But once again, the statistical interaction of drug treatment condition and test odor was not significant $(F=0.6 ; p=N S)$. Thus, discrimination was not affected by any treatment.

\section{AmOAR sequence predicts an $A$. mellifera} octopamine receptor

To use RNA interference, we first identified a putative octopamine receptor from honeybee, A. mellifera, brain tissue (AmOAR) (Fig. 4a). To this end, an AmOAR cDNA was isolated by use of low-stringency hybridization. We compared the sequence of the isolated AmOAR fragment with the sequences of other insect octopamine receptors. First, we aligned our predicted AmOAR amino acid sequence with $\mathrm{OAMB}$, an OAR from D. melanogaster (Dm) (Han et al., 1998) and with an OAR from Bombyx mori 
(Bm) (Von Nickisch-Rosenegk et al., 1996). Comparison between AmOAR and OAMB resulted in $82 \%$ identity, whereas AmOAR and the OAR from B. mori had only 54\% identity. Among insects, the highest sequence identity was observed between AmOAR and the fruit fly OAMB receptor (Fig. $4 b$ ). Furthermore, an amino acid sequence comparison was also done across several other invertebrates. We included sequences of the Oa1, an OAR from Lymnaea stagnalis (Ls) (Gerhardt et al., 1997), and an OAR from Aplysia kurodai (Ak) (Chang et al., 2000). When the AmOAR sequence was compared with $L$. stagnalis and A. kurodai sequences, alignment results showed $68 \%$ and $56 \%$ identity, respectively (Fig. 4b).

We also compared AmOAR with AmBAR1 (31 aa fragment), one of the seven unique biogenic amine receptor clones isolated from honeybee (Ebert et al., 1998). The AmBAR1 sequence was fully identical with AmOAR (data not shown), which indicates that these two clones may be from the same gene. Furthermore, the AmOAR sequence was found to have only $52 \%$ identity with a dopamine $\mathrm{D}_{1}$ receptor from A. mellifera (Blenau et al., 1998). This level of similarity was 54 and 51\%, similar to two different D1-like dopamine receptors from Drosophila (Gotzes et al., 1994; Sugamon et al., 1995; Feng et al., 1996; Han et al., 1996). That AmOAR is more similar to the fruit fly OAMB than to a honeybee dopamine receptor provides an additional indication that the AmOAR sequence encodes an octopamine receptor.

\section{AmOAR-dsRNA injection into AL results in reduced AmOAR protein levels}

dsRNA directs RNAi by degrading sequence-specific mRNA, which results in specific loss of function (Kennerdell and Carthew, 1998; Montgomery and Fire, 1998; Montgomery et al., 1998). To investigate the effect of dsRNA on receptor protein levels, we injected AmOAR dsRNA into the AL of honeybee brains. Polyclonal antiserum raised against peptide selected from an intracellular region of the AmOAR sequence reveals a $78 \mathrm{kDa}$ band in Western blot analysis of the control (vehicle-injected) AL homogenate (Fig. $5 a$ ). This band was not present in control AL homogenate when probed with preimmune serum (data not shown). Furthermore, there was a significant reduction specifically in the $78 \mathrm{kDa}$ band when immunoblotting was performed with AmOAR antiserum in the presence of the corresponding peptide $\left(F_{(1,13)}=\right.$ 61.24; $p<0.0001$ ), which provides an additional indication that the $78 \mathrm{kDa}$ band is recognized by the anti-peptide antibody rather than the secondary antibody (Fig. $5 a$ ). This band was also significantly reduced in the dsRNA-injected AL homogenate compared with control $\left(F_{(1,13)}=33.07 ; p<0.0001\right)$ (Fig. $\left.5 b\right)$.

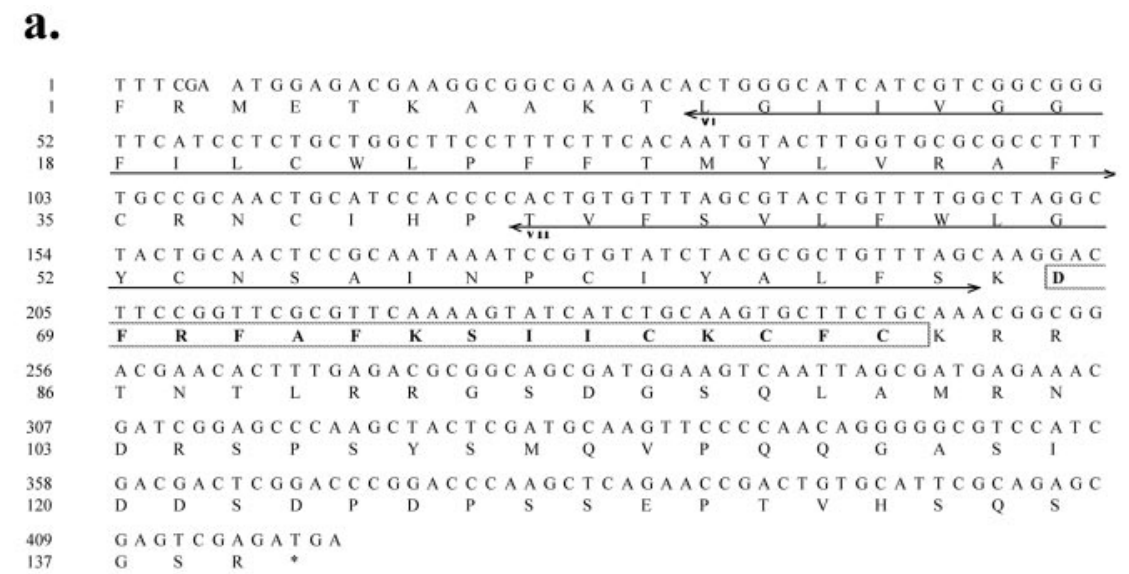

b.

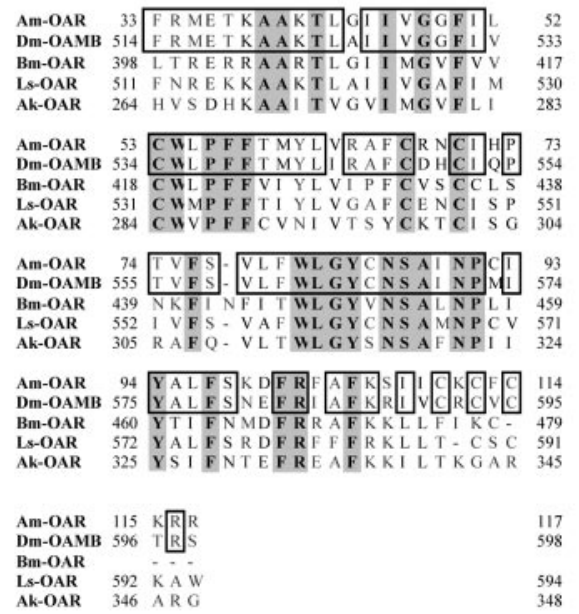

Figure 4. Partial sequence of AmOAR and its alignment with other octopamine receptors. $a$, Partial nucleotide and amino acid sequence of AmOAR (GenBank accession number AYZ63366). Transmembrane regions VI and VII are underlined. Amino acid residues selected for peptide synthesis are indicated by the box. b, Amino acid alignment of AmOAR receptor with the D. melanoreceptor (Lm-0AR; u62771), and A. kurodai octopamine receptor (Ak-0AR; AF117654). Residues conserved among all five octopamine receptors are shaded in gray. A dash is used to indicate a gap in the sequence. Amino acids conserved among Am-OAR and Drosophila dopamine D1 receptor (DAMB; AAB08000), Drosophila dopamine D1-like receptor (D1-like; AAA85716), and Drosophila dopamine D2 receptor (DopR2; Q24563). Residues conserved among all five proteins are shaded in gray. Residues conserved among all dopamine receptors are indicated by dashed lines. Residues conserved among Am0AR and AmD0P1 are boxed.

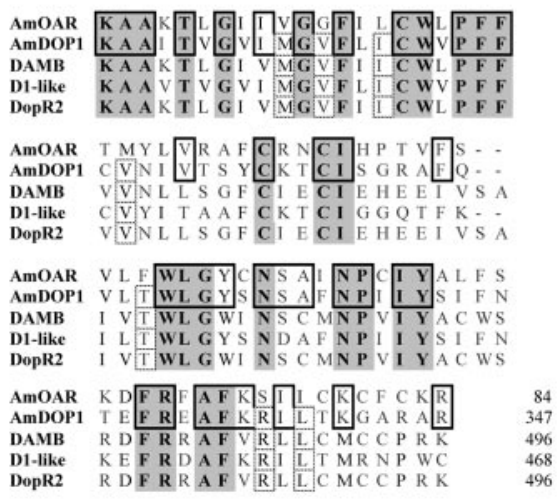


(a)

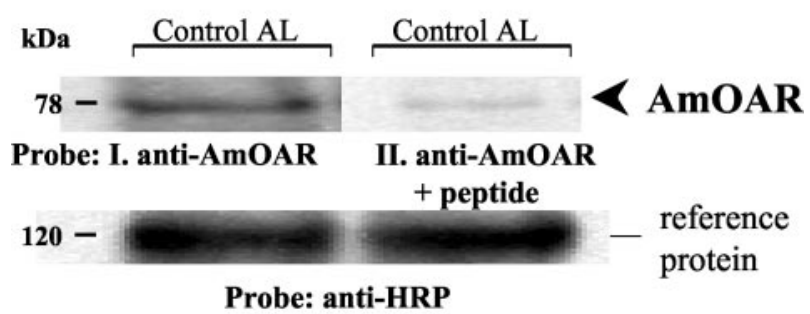

(b)

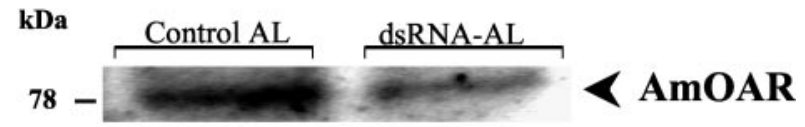

Probe: anti-AmOAR

120

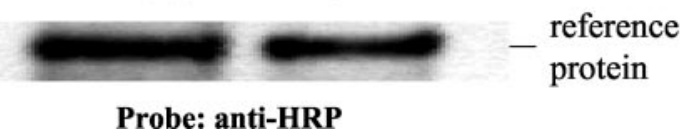

Probe: anti-HRP

Figure 5. AmOAR dsRNA impairs OAR protein translation in AL of honeybee. $a$, Western blotting was performed on protein fractions from control AL homogenates. I, Nitrocellulose membrane was probed with anti-AmOAR antiserum. A $78 \mathrm{kDa}$ protein (arrow) was recognized by the anti-AmOAR antiserum. II, Nitrocellulose membrane was probed with anti-AmOAR antiserum preadsorbed with corresponding peptide resulted in significant decrease in intensity of $78 \mathrm{kDa}$ band $(p<0.0001)$. The same blots were stripped and reprobed with anti-HRP antiserum (for reference). $b$, Western blotting was performed on protein fractions from control and $24 \mathrm{hr}$-dsRNA-injected AL homogenates. Nitrocellulose membrane was probed with antiAmOAR antiserum. A significant reduction in $78 \mathrm{kDa}$ band was observed in dsRNA injected AL homogenate $(p<0.0001)$. The blot was stripped and reprobed with anti-HRP antiserum (for reference) to confirm that equivalent amount of protein was loaded in each lane.

ified from those used with MAS (Fig. 1a) because of the need to allow a longer time for the dsRNA to degrade the target RNA and to allow for receptor turnover.

According to the protocol in which dsRNA treatment occurred before conditioning (Fig. 1b.1), 80\% of the subjects in the control group, in which injection buffer was injected into the AL, responded to the conditioned odor by the third acquisition trial (Fig. $6 a$ ). In the AmOAR dsRNA-treated group, only 15\% of the subjects responded to conditioned odor by the fifth trial. That is, dsRNA produced $\sim 80 \%$ inhibition of the acquisition response $\left(F_{(1,69)}=67.13 ; p<0.0001\right)$. Injection of AmOAR dsRNA before acquisition also affected recall (Fig. 6b). The AmOAR dsRNAtreated group exhibited a 50\% reduction in recall compared with the control group $(F=4.3 ; p<0.05)$. The response levels to $\mathrm{C}, \mathrm{S}$, and $\mathrm{D}$ were significantly different $(F=3.4 ; p<0.05)$. But as with MAS, discrimination was unaffected, which is revealed by the lack of a significant interaction between treatment and test odor $(F=0.6 ; p=\mathrm{NS})$.

We performed one replication of this experiment in which the investigator (B.H.S.) was blind to the treatment condition until all data were collected and analyzed. In this replicate, 50 and $58 \%$ of control subjects $(n=27)$ responded to odorant by the third and fourth acquisition trials. In contrast, only $22.2 \%$ of dsRNAtreated subjects $(n=27)$ responded over trials 3 through $6(t=$ $2.0 ; \mathrm{df}=52 ; p=0.05)$. All subjects were also tested with the CS odorant 90 min after conditioning. During this test, $53.8 \%$ of control and $18.5 \%$ of dsRNA-treated subjects responded $\left(\chi^{2}=\right.$ $6.6 ; p<0.05)$.

Treatment with dsRNA also failed to impair the US in an experiment identical to that for MAS described above. Over suc-
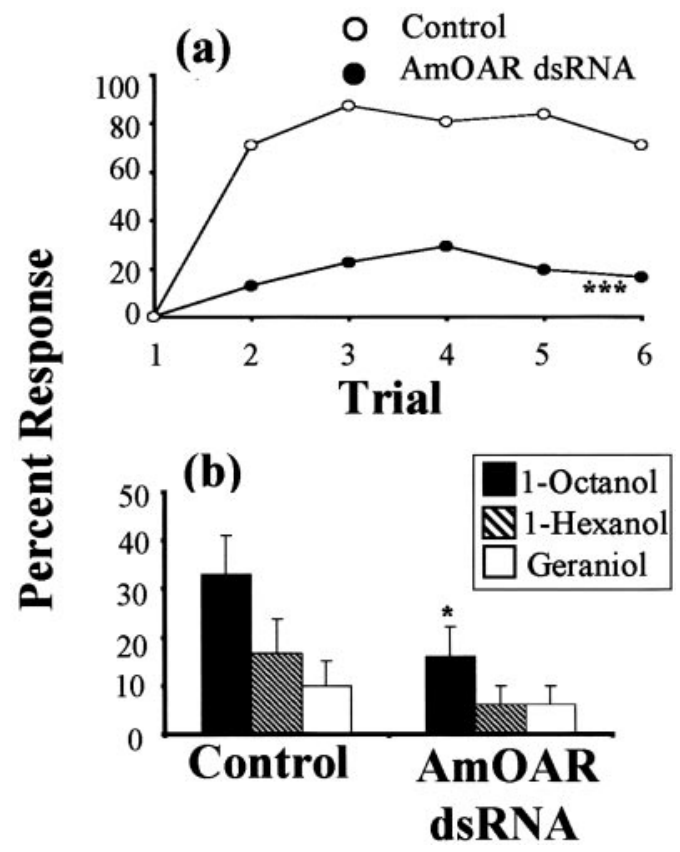

Figure 6. The effect of AmOAR dsRNA on acquisition and/or recall testing. a, Acquisition to conditioned odor (C). In this experiment, $2 \mathrm{hr}$ after surgery, subjects received $4 \mathrm{nl}$ of injection buffer-Am0AR dsRNA (500 pg) in each AL. Twenty-four hours later, subjects were conditioned with odor C. $b$, Ninety minutes later, subjects were tested with C, S, and D in a randomized manner. Asterisk indicates significant difference of respective point from control group $\left({ }^{*} p<\right.$ $\left.0.01 ;{ }^{* * *} p<0.0001\right)$. Sample sizes: saline $(n=31)$, Am0AR dsRNA $(n=31)$.

cessive feedings, subjects in the two treatment groups responded equally well to sucrose application to the antennas and consumed statistically equal amounts of sucrose solution $(t=0.2 ; \mathrm{df}=29$; $p=\mathrm{NS})$. Subjects treated with injection buffer $(n=15)$ consumed an average of $26.1 \mu \mathrm{l}$ (SEM, 7.0), and subjects treated with dsRNA $(n=16)$ consumed $27.0 \mu \mathrm{l}$ (SEM, 7.2).

\section{AmOAR dsRNA interferes with recall independent of acquisition}

To examine the effect of preconditioning on recall, subjects were conditioned before treatment with AmOAR dsRNA (Fig. 1b.2). Twenty-four hours later, subjects were tested for recall. Figure $7 a$ shows the acquisition curves of two groups of bees. In both groups, $\sim 65 \%$ of the subjects responded to the conditioned odor by trial 3. Two hours after conditioning, one group was treated with injection buffer and the other with AmOAR dsRNA. Twenty-four hours later, we found 50\% inhibition of recall in the AmOAR dsRNA-treated group compared with control (Fig. 7b). The patterns of statistical significance for dsRNA versus control $(F=7.4 ; p<0.01)$, comparison of test odor $(F=3.0 ; p<0.05)$, and interaction were identical to those for the previous experiment (Fig. 6).

Specificity of AmOAR dsRNA-mediated effect on acquisition If the effects we observed from dsRNA treatment arose nonspecifically from dsRNA treatment rather than from the specific degradation of the AmOAR RNA, then similar behavioral effects should occur with other types of dsRNA. To determine the specificity of the AmOAR dsRNA-mediated effect, we tested the effect of dsRNA from fred, a developmental gene from Drosophila (Chandra et al., 2003). Furthermore, we also tested the effect of $E$. coli tRNA and yeast tRNA. We found that acquisition curves in groups treated with fruit fly dsRNA $\left(F_{(1,114)}=0.0001 ; p=N S\right)$, 


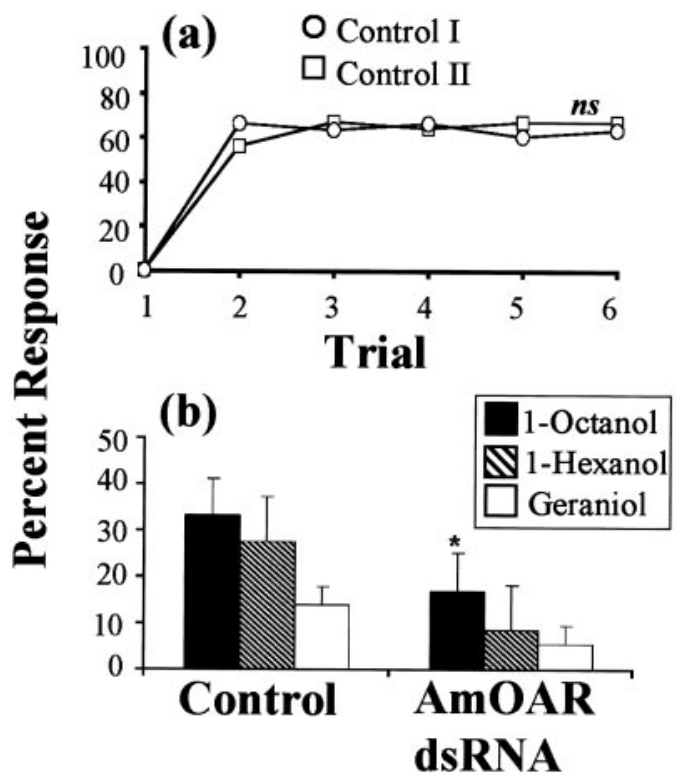

Figure 7. The effect of preconditioning on AmOAR dsRNA-mediated recall response. $a$, Conditioning of subjects in 2 control groups. Two hours after conditioning, in one group, injection buffer was injected into each AL. In the second group, $4 \mathrm{nl}$ of AmOAR dsRNA (500 pg) was injected into each AL. b, Twenty-four hours later, subjects were tested with C, S, and D in a randomized manner. Asterisk indicates significant difference of respective point from control group ( $\left.{ }^{*} p<0.05\right)$. Sample sizes: control $(n=36), \operatorname{Am0AR}$ dsRNA $(n=35)$. ns, No significant difference.

yeast tRNA $\left(F_{(1,55)}=0.0001 ; p=\mathrm{NS}\right)$, or $E$. coli tRNA $\left(F_{(1,63)}=\right.$ $0.82 ; p=$ NS) were not significantly different from control (Fig. 8). Recall responses were also unaffected (data not shown). These data suggest that the effect we observed on acquisition and recall were specific to treatment with AmOAR dsRNA.

\section{MAS or AmOAR dsRNA injection in optic lobes does not affect acquisition or recall}

As an additional control to evaluate the possibility that MAS or AmOAR dsRNA effects may occur because of disruption of OAR in neighboring areas of the brain, such as the mushroom bodies (MB in Fig. 1), we treated the optic lobes (OLs) in two different experiments. If the behavioral effects on treatment of the $\mathrm{AL}$ occur because of spread into the $\mathrm{MB}$, then the drug should spread equally well into the MB from the OL, and the same behavioral effects would be evident.

Acquisition curves of groups treated with $200 \mu \mathrm{M} \operatorname{MAS}\left(F_{(1,85)}=\right.$ $0.91 ; p=\mathrm{NS})$ or with 500 pg dsRNA $\left(F_{(1,40)}=0.90 ; p=\mathrm{NS}\right)$ in each AL failed to differ from their respective controls (Fig. 9a,c). Recall was also unaffected (Fig. 9b,d). This suggests that the effect of MAS and dsRNA is localized to AL, at least over the time frame during which we treated and tested our subjects.

\section{Subjects recover from MAS but not from AmOAR dsRNA}

We performed an experiment in which subjects were treated with MAS (200 $\mu \mathrm{M})$, dsRNA (500 pg), or the respective controls, and they were then conditioned to an odorant CS as above but at different time intervals after injection. Subjects conditioned 20 min after treatment with MAS responded significantly less than equivalent control subjects (Fig. 10a) $\left(F_{(1,63)}=15.82 ; p<\right.$ $0.0002)$. In contrast, saline and MAS treatment groups both displayed equivalently high levels of acquisition performance $24 \mathrm{hr}$ after injection treatment $(t=0.14 ; \mathrm{df}=30 ; p=\mathrm{NS})$. Subjects treated with AmOAR dsRNA were conditioned 24 and $48 \mathrm{hr}$ after

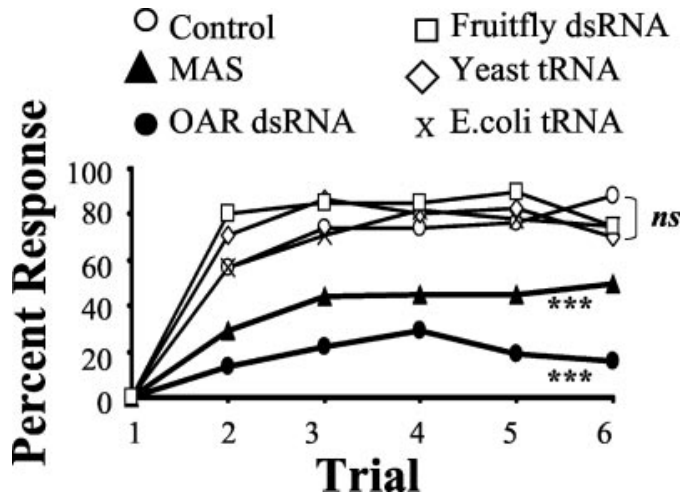

Figure 8. Other dsRNA types do not block acquisition response. On acquisition to conditioned odor $(C)$ : two hours after surgery, subjects received $4 \mathrm{nl}$ of either injection buffer-Drosophila dsRNA (500 pg), buffer-yeast tRNA (500 pg), or buffer-E. coli tRNA (500 pg) in each AL. Twenty-four hours later, subjects were conditioned with C. Asterisk indicates significant difference of respective response from control group $\left({ }^{* * *} p<0.0001\right)$. Sample size: control $(n=23)$, Drosophila dsRNA ( $n=37)$, yeast tRNA $(n=26)$, E. coli tRNA ( $n=43)$. ns, No significant difference was detected among these four groups.

treatment (Fig. 10b). At both time intervals, dsRNA treated subjects revealed equivalent levels of acquisition performance $(t=$ $0.6 ; \mathrm{df}=35 ; p=\mathrm{NS})$, and in each case it is significantly lower than that exhibited by the appropriate control subjects $\left(F_{(3,44)}=9.4\right.$; $p<0.001)$.

\section{Discussion}

Our results implicate OA as an important component of the reward pathway in the honeybee AL. Physiological recordings from an octopaminergic interneuron (VUMmx1), which arborizes broadly in several neuropils of the honeybee brain, have implicated OA in the sucrose reward pathway (Hammer, 1993; Hammer and Menzel, 1998). VUM normally responds to sucrose stimulation of the mouthparts but not to odor. After pairing of odor with sucrose, VUMmx1 responds to odor. Furthermore, replacement of sucrose with depolarization of VUM can drive conditioning (Hammer and Menzel, 1998). Because VUM arborizes in most if not all glomeruli of the AL, it presumably is capable of representing the presence of reinforcement at this level of sensory processing. Furthermore, because VUM responds to odor after conditioning but not before, odor takes on the capacity to activate the US (VUM) pathway (Holland, 1993).

We evaluated the role of OA release in the AL in representing conditioned odors. Previous studies attempted to augment OA by microinjection into the AL (Hammer and Menzel, 1998), or it was injected into the mushroom bodies in honeybees in which biogenic amines had been depleted by reserpine treatment (Menzel et al., 1999). These studies showed that augmentation of OA affected appetitive conditioning using sucrose. As in Hammer and Menzel (1998), we evaluated the effect of OA-mediated plasticity in the AL, which is the first-order olfactory neuropil that feeds information into the mushroom bodies (Strausfeld, 1976; Mobbs, 1982). But there are two important differences between our study and earlier studies. First, we disrupted the receptor component of the OA pathway. We show that acquisition and subsequent conditioned responding to an odor is impaired, which reveals that OA is important for processing olfactory information in the AL.

Second, insight into the precise role played by OA in the AL network can be gained by an evaluation of the implications of the experimental designs that we chose to use. We evaluated acquisi- 
(a)

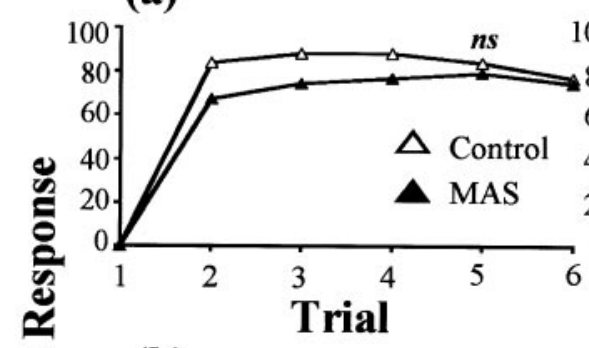

(b)
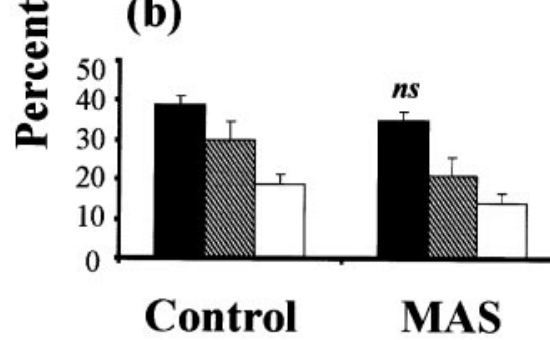

(c)

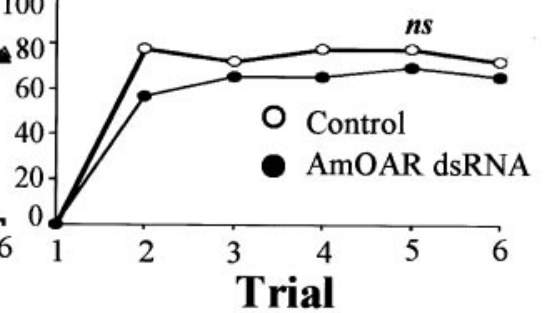

(d)

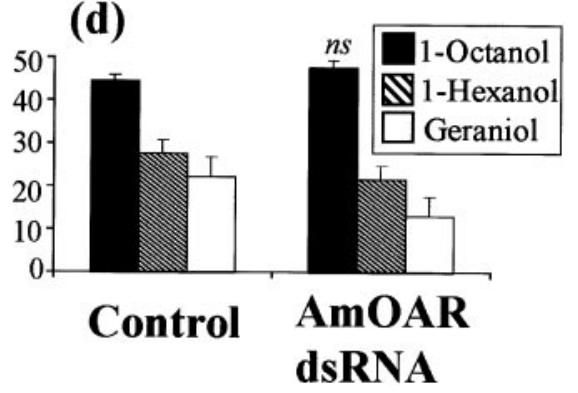

Figure 9. MAS and AmOAR dsRNA do not block acquisition when applied to OL. a, Acquisition response to conditioned odor (C). Two hours after surgery, subjects received $4 \mathrm{nl}$ of saline-MAS solution (200 $\mu \mathrm{m})$ in each OL. Ten minutes later, subjects were conditioned with six acquisition trials of 30 sec intertrial interval. $b$, Ninety minutes after conditioning, $4 \mathrm{nl}$ of saline or MAS was applied again in each AL. Ten minutes later, subjects were tested with odors C, S, and D in a randomized manner. C, Two hours after surgery, subjects received $4 \mathrm{nl}$ of injection buffer-AmOAR dsRNA (500 pg) in each OL. Twenty-four hours later, subjects were conditioned with odor $C . d$, Ninety minutes later, subjects were tested with $C, S$, and D in a randomized manner. Sample size: saline-saline $(n=43)$, MAS-MAS $(n=43)$, buffer $(n=18)$, Am0AR dsRNA ( $n=23)$. ns, No significant difference was detected among control and treated group.

tion by monitoring conditioned responses over six conditioning trials (Menzel, 1990). Many studies have used a variety of controls to reveal that this procedure produces robust and longlasting associative conditioning (Bitterman et al., 1983). After conditioning, and at a time when the olfactory memory should have consolidated into a more stable, intermediate state (Müller, 1997; Tully, 1998; Müller and Hildebrandt, 2002), we evaluated recall toward the conditioned odorant and generalization to other "novel" odorants. Generalization in this paradigm occurs as a function of molecular similarity of the test odorants to the conditioned odorant (Smith and Menzel, 1989; Stopfer et al., 1997).

We evaluated subjects in an experimental protocol that allows for investigation of several possible drug effects. Drug treatment occurred before conditioning, before recall testing, or before both phases. This protocol can determine whether the drug creates a state-dependent memory (Spear et al., 1990). In that case, recall and generalization responses would be normal in groups in which drug conditions at testing match those of conditioning (in saline-saline and drug-drug groups), because the drug becomes part of the conditioning context in such a way that it affects perception of the stimuli. This protocol also reveals whether acquisition and recall can be disrupted independently by drug treatment (in drug-saline and saline-drug conditions).

We show that disruption of AmOAR in the AL impaired acquisition and recall when drug treatment occurred before each of those phases. But this impairment is not state dependent, because disruption of AmOAR before both phases failed to reestablish conditioned responding. Impairment of acquisition indicates that blockade of OA neurotransmission in some way diminished the impact of the US, which might be expected given the physiological data from VUM (Hammer, 1993).

It is more surprising that disruption of the AmOAR before recall testing but not before acquisition also produces a response decrement. This indicates that during acquisition, VUM becomes an integral part of the AL network that represents a conditioned odorant. Therefore, VUM is not just a US pathway that is activated by odor after conditioning. To impair recall, VUM would have to be essential for reactivation of the AL network so that the olfactory memory, part of which is consolidated downstream in the mushroom body, can be accessed. The precise nature of this effect is still unclear. For example, association of odor with sucrose reinforcement might enhance the representation of that odor in the AL so as to make it more detectable or salient. Blockade of AmOAR might then be expected to block acquisition or recall if an intact OAR pathway is necessary for development and expression of this enhancement, as we have suggested. Several other possibilities could also account for our results, such as a qualitative change in the perceptual qualities of an odor as a result of conditioning. Additional computational modeling (Linster and Smith, 1997) may help to reveal new, testable hypotheses.

This pattern of results contrasts with results from identical experiments that blocked GABA or nitric oxide pathways in the AL. Blockade of either pathway does not impair and may even augment acquisition (Stopfer et al., 1997; Hosler et al., 2000; Daly et al., unpublished observations). However, these treatments impair the accuracy of recall either by disrupting the specificity of the activity pattern in the AL network (Stopfer et al., 1997; Hosler et al., 2000) or perhaps by raising the overall responsiveness of the AL network to stimulation (Daly et al., unpublished observations).

Thus, several modulatory pathways appear to have different influences on the AL circuitry. Physiological analyses and computational models have begun to reveal how the AL circuitry responds to association of odors with reinforcing events. In the honeybee and in the moth Manduca sexta, association of an odor with sucrose reinforcement changes the activity of the AL network (Faber et al., 1999; Daly et al., unpublished observations). We would therefore predict that blockade of OA neurotransmission in the honeybee AL or in the moth, perhaps blockade of serotonin (Dolzer et al., 2001) would prevent these changes from occurring. Furthermore, to be consistent with our data, this impairment should occur during both acquisition and recall testing. Linster and Smith (1997) developed a computational model of the honeybee AL that incorporated a VUM-like neuron that has associative properties like its natural analog (Hammer, 1993). Although it was not explicitly tested, the model VUM grew to participate in the network as we have proposed here. Additional computational efforts are now needed to clarify what network properties would give rise to the properties of OA neurotransmission that we report.

We used two different means for blockade of OA neurotransmission in the AL, because each has particular advantages and disadvantages. Combination of the two provides a stronger argument than would either one alone. We chose MAS because it has 


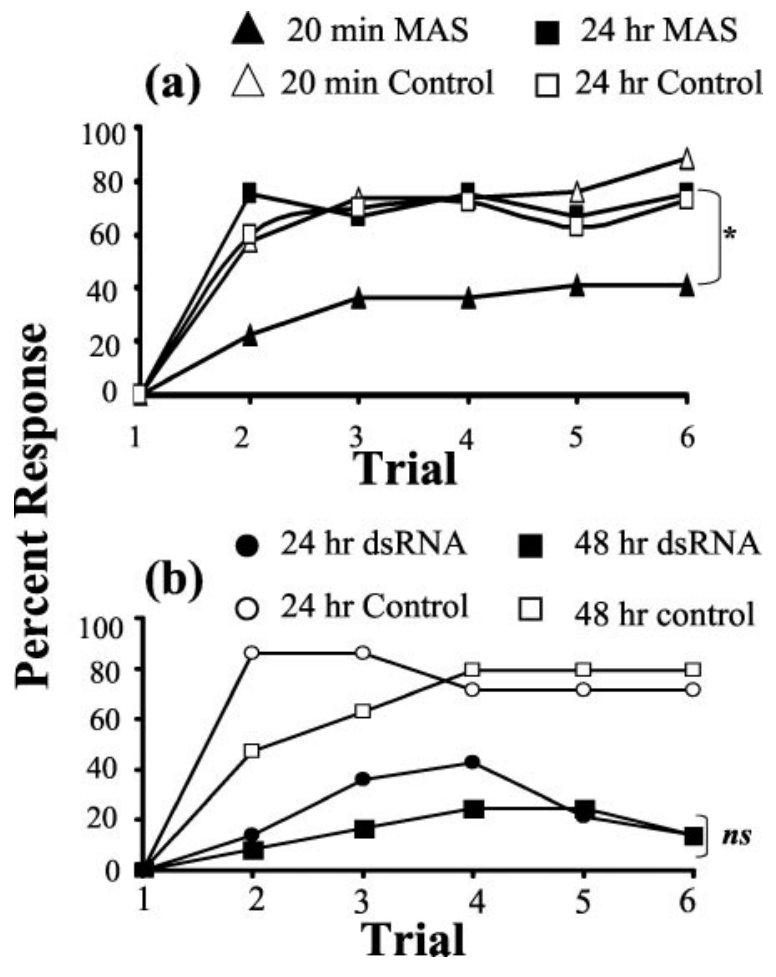

Figure 10. Effect of time intervals after injection of MAS or AmOAR dsRNA on the acquisition response. $a$, Two hours after surgery, subjects received $4 \mathrm{nl}$ of saline or MAS solution $(200 \mu \mathrm{m})$ in each AL. Twenty minutes later, subjects were conditioned with six acquisition trials of $30 \mathrm{sec}$ intertrial interval. Twenty-four hours later, subjects were reconditioned with odor C. Sample size: saline ( $n=42) 20$ min after injection; $\operatorname{MAS}(n=22) 20$ min after injection; saline $(n=12)$ $24 \mathrm{hr}$ after injection; $\operatorname{MAS}(n=20) 24 \mathrm{hr}$ after injection. Asterisk indicates significant difference between 20 min and $24 \mathrm{hr}$ MAS after injection response $\left.{ }^{*} p<0.02\right) . b$, Two hours after surgery, subjects received $4 \mathrm{nl}$ of AmOAR dsRNA solution ( $500 \mathrm{pg}$ ) in each AL. Twenty-four hours later, subjects were conditioned with six acquisition trials of $30 \mathrm{sec}$ intertrial interval. Forty-eight hours later, subjects were reconditioned with odor C. Sample size: injection buffer $(n=7) 24 \mathrm{hr}$ after injection; AmOAR dsRNA ( $n=14) 24 \mathrm{hr}$ after injection; injection buffer $(n=10) 48 \mathrm{hr}$ after injection; AmOAR dsRNA ( $n=14) 48 \mathrm{hr}$ after injection. ns, No significant difference was detected between 24 and $48 \mathrm{hr}$ after injection.

a relatively high binding affinity for neuronal OAR of insects (Degen et al., 2000). MAS produced a dose-dependent decrease in performance. It has the advantage that the full power of a dual-injection protocol, described above, can be used. But the disadvantage, particularly at higher concentrations, is that the specificity for OAR would be expected to decrease. Thus, any effect might be a result of targeting of other biogenic amine receptors in the AL.

RNAi, conversely, would be expected to be very specific to the targeted mRNA (Fire et al., 1998; Montgomery and Fire, 1998; Montgomery et al., 1998; Misquitta and Paterson, 1999; Elbashir et al., 2001). It has been used successfully in the insect CNS (Billuart et al., 2001; Dzitoyeva et al., 2001), and it has been used to disrupt neuronal nitric oxide synthase gene function in a mollusk (Korneev et al., 2002). More recently, it was used to silence a developmental gene in the honeybee (Amdam et al., 2003). In the latter three examples, whole animals or embryos were treated with dsRNA, which provides an indication that dsRNA can enter cells in the CNS. As in our case, the mechanism of uptake into cells is as yet unknown. That issue notwithstanding, the disadvantage to use of dsRNA is that, once induced, RNAi produces a long-lasting if not indeed permanent effect, which does not easily allow for assessment of effects on acquisition independent of recall. If it is induced before acquisition, it can be expected that the OAR will be depleted at the time of testing also. Spread of dsRNA is also an issue. In our experiments, the effects of both treatment types were limited to the $\mathrm{AL}$, at least over the time periods we used, because in neither case did treatment of nearby neuropils produce a detectable effect in our behavioral assay.

The specificity of RNAi depends on whether the sequence we used to generate dsRNA was from an OAR. The amino acid sequence of our clone was $82 \%$ identical to the putative ortholog OAR sequence in Drosophila mushroom bodies (Han et al., 1998). Furthermore, according to the size $(78 \mathrm{kDa})$ of the band recognized by our anti-peptide antiserum in an AL homogenate, it is likely to be an OAR. A neuronal OAR was characterized previously by photoaffinity labeling from nerve tissue of the desert locust, Schistocerca gregaria (Roeder and Nathanson, 1994) and light organs of the firefly, Photinus pyralis (Nathanson et al., 1989). Labeling studies revealed an OAR in the range of 55-79 $\mathrm{kDa}$, which is in the range of our observed value for AmOAR.

Interestingly, AmOAR dsRNA produced only a $40 \%$ reduction in OAR protein synthesis $24 \mathrm{hr}$ after dsRNA treatment. This partial reduction may reflect incomplete receptor turnover. Alternatively, it could be because of the presence of alternatively spliced variants of the OAR, which are common in G-proteincoupled receptor genes (Blein et al., 2000; Hosie et al., 2001). tBlastn searches of AmOAR with Anopheles gambiae and D. melanogaster genome sequences show that a genomic fragment with an open reading frame (encoding $\sim 171 \mathrm{aa}$ ), which includes the sequence we used to generate the peptide antibody, was repeated in close proximity in the respective genomes (data not shown). Furthermore, cDNA corresponding to two spliced variants for the $D$. melanogaster OAR suggests that the same gene encodes these variants (NCBI, accession numbers AJ007618 and AJ007617). If this is the case in the honeybee, then a $40 \%$ reduction in protein might be explained by the possibility that dsRNA is degrading only one of the mRNA variants.

In summary, we have provided evidence that OA serves as a link between an olfactory CS and a sucrose US in the AL of the honeybee, in which pathways that process those two types of stimuli converge. Therefore, the AL is a site in which part of the olfactory memory consolidates. It remains to be determined why a component of olfactory memory occurs at this early level of processing. Recent studies with the moth $M$. sexta have established alterations in neural activity patterns in the AL when odors are associated with reinforcement (Daly et al., unpublished observations). The combination of pharmacological and molecular manipulation of modulatory pathways, as we report here, with physiological methods will be necessary to elucidate the solutions to this problem.

\section{References}

Altschul SF, Madden TM, Schaffer AA, Zhang J, Zhang Z, Miller W, Lipman DJ (1997) Gapped BLAST and PSI-BLAST: a new generation of protein database search programs. Nucleic Acids Res 25:3389-3402.

Amdam GV, Simoes ZLP, Guidugli KR, Norberg K, Omholt SW (2003) Disruption of vitellogenin gene function in adult honeybees by intraabdominal injection of double-stranded RNA. BMC Biotechnol 3:1.

Billuart P, Winter CG, Maresh A, Zhao X, Luo L (2001) Regulating axon branch stability: the role of 190 RhoGAP in repressing a retraction signaling pathway. Cell 107:195-207.

Bitterman ME, Menzel R, Fietz A, Schafer S (1983) Classical conditioning of proboscis extension in honeybees (Apis mellifera). J Comp Physiol 97:107-119.

Blein S, Hawrot E, Barlow P (2000) The metabotropic GABA receptor: molecular insights and their functional consequences. Cell Mol Life Sci 57:635-650.

Blenau W, Erber J, Baumann A (1998) Characterization of a dopamine D1 
receptor from Apis melliferd: cloning, functional expression, pharmacology, and mRNA localization in the brain. J Neurochem 70:15-23.

Blenau W, Baumann A (2001) Molecular and pharmacological properties of insect biogenic amine receptors: lessons from Drosophila melanogaster and Apis mellifera. Arch Insect Biochem Physiol 48:13-38.

Chandra S, Ahmed A, Vaessin H (2003) The Drosophila IgC2 domain protein Friend-of-Echinoid, a paralogue of Echinoid, limits the number of sensory organ precursors in the wing disc and interacts with the Notch signaling pathway. Dev Biol 265:302-316.

Chang DJ, Li XC, Lee YS, Kim HK, Kim US, Cho NJ, Lo X, Weiss KR, Kandel ER, Kaang BK (2000) Activation of heterologously expressed octopamine receptor coupled only to adenylyl cyclase produces all the features of presynaptic facilitation in Aplysia sensory neurons. Proc Natl Acad Sci USA 97:1829-1834.

Degen J, Gewecke M, Roeder T (2000) Octopamine receptors in the honey bee and locust nervous system: pharmacological similarities between homologous receptors of distantly related species. Br J Pharmacol 130:587-594.

Dolzer J, Krannich S, Fischer K, Stengl M (2001) Oscillations of the transepithelial potential of moth olfactory sensilla are influenced by octopamine and serotonin. J Exp Biol 204:2781-2794.

Dubnau J, Grady L, Kitamoto T, Tully T (2001) Disruption of neurotransmission in Drosophila mushroom body blocks retrieval but not acquisition of memory. Nature 411:476-480.

Dzitoyeva S, Dimitrijevie N, Manev H (2001) Intra-abdominal injection of double-stranded RNA into anesthetized adult Drosophila triggers RNA interference in the central nervous system. Mol Psychiatry 6:665-670.

Ebert PR, Rowland JE, Toma DP (1998) Isolation of seven unique biogenic amine receptor clones from the honey bee by library scanning. Insect $\mathrm{Mol}$ Biol 7:151-162.

Elbashir SM, Lendeckel W, Tuschl T (2001) RNA interference is mediated by 21-and 22-nucleotide RNAs. Genes Dev 15:188-200.

Erber J, Kloppenburg P, Scheidler A (1993) Neuromodulation by serotonin and octopamine in the honeybee: behaviour, neuroanatomy and electrophysiology. Experientia 49:1073-1083.

Faber T, Joerges J, Menzel R (1999) Associative learning modifies neural representations of odors in the insect brain. Nat Neurosci 2:74-78.

Feng G, Hannan F, Reale V, Hon YY, Kousky CT, Evans PD, Hall LM (1996) Cloning and functional characterization of a novel dopamine receptor from Drosophila melanogaster. J Neurosci 16:3925-3933.

Fire A, Xu S, Montgomery MK, Kostas SA, Diiver, SE, Mello CC (1998) Potent and specific genetic interference by double-stranded RNA in Caenorhabditis elegans. Nature 391:806-811.

Fletcher ML, Wilson DA (2002) Experience modifies olfactory acuity: acetylcholine-dependent learning decreases behavioral generalization between similar odorants. J Neurosci 22:RC201(1-5).

Gerhardt CC, Bakker RA, Piek GJ, Planta RJ, Vreughdenhil E, Leysen JE, Neerikhuizen H (1997) Molecular cloning and pharmacological characterization of a molluscan octopamine receptor. Mol Pharmacol 51:293-300.

Gotzes F, Belfanz S, Bauman A (1994) Primary structure and functional characterization of a Drosophila dopamine receptor with high homology to human D1/5 receptors. Receptors Channels 2:131-141.

Hammer M (1993) An identified neuron mediates the unconditioned stimulus in associative olfactory learning in honeybees. Nature 366:59-63.

Hammer M, Menzel R (1998) Multiple sites of associative odor learning as revealed by local brain microinjections of octopamine in honeybees. Learn Mem 5:146-156.

Han KA, Millar NS, Grotewiel MS, Davis RL (1996) DAMB, a novel dopamine receptor expressed specifically in Drosophila mushroom bodies. Neuron 16:1127-1135.

Han KA, Millar NS, Davis RL (1998) A novel octopamine receptor with preferential expression in Drosophila mushroom bodies. J Neurosci $18: 3650-3658$.

Hildebrandt H, Müller U (1995) Octopamine mediates rapid stimulation of protein kinase A in the antennal lobe of honeybees. J Neurobiol 27:44-50.

Hildebrand JG, Shepherd GM (1997) Mechanisms of olfactory discrimination: converging evidence for common principles across phyla. Annu Rev Neurosci 20:595-631.

Holland PC (1993) Cognitive aspects of classical conditioning. Curr Opin Neurobiol 3:230-236.

Hosie AM, Buckingham SD, Presnail JK, Sattelle DB (2001) Alternative splicing of a Drosophila GABA receptor subunit gene identifies determinants of agonist potency. Neuroscience 102:709-714.

Hosler JS, Buxton KL, Smith BH (2000) Impairment of olfactory discrimination by blockade of GABA and nitric oxide activity in the honey bee antennal lobes. Behav Neurosci 114:514-525.

Jan LY, Jan YN (1982) Antibodies to horseradish peroxidase as specific neuronal markers in Drosophila and in grasshopper embryos. Proc Natl Acad Sci USA 79:2700-2704.

Kendrick KM, Levy F, Keverne EB (1992) Changes in the sensory processing of olfactory signals induced by birth in sheep. Science 256:833-836.

Kendrick KM, Guevara-Guzman R, Zorrilla J, Hinton MR, Broad KD, Mimmack M, Ohkura S (1997) Formation of olfactory memories mediated by nitric oxide. Nature 388:670-674.

Kennerdell JR, Carthew RW (1998) Use of dsRNA-mediated genetic interference to demonstrate that frizzled and frizzled 2 act in the wingless pathway. Cell 95:1017-1026.

Knust E, Dietrich U, Tepass U, Bremer KA, Weigel D, Vaessin H, CamposOrtega JA (1987) EGF homologous sequences encoded in the genome of Drosophila melanogaster and their relation to neurogenic genes. EMBO J 6:761-766.

Korneev SA, Kemens I, Straub V, Staras K, Korneeva EI, Kemenes G, Benjamin PR, O'Shea M (2002) Suppression of nitric oxide (NO)dependent behavior by double-stranded RNA-mediated silencing of a neuronal NO synthase gene. J Neurosci 22:RC227(1-5).

Laemmli UK (1970) Cleavage of structural proteins during the assembly of the head of bacteriophage T4. Nature 227:680-685.

Levy F, Gervais R, Kindermann U, Orgeur P, Picketty V (1990) Importance of noradrenergic receptors in the olfactory bulb of sheep for recognition of lambs. Behav Neurosci 104:464-469.

Linster C, Smith BH (1997) A computational model of the response of honey bee antennal lobe circuitry to odor mixtures: overshadowing, blocking and unblocking can arise from lateral inhibition. Behav Brain Res 87:1-14.

McGuire SE, Le PT, Davis RL (2001) The role of Drosophila mushroom body signaling in olfactory memory. Science 293:1330-1333.

Menzel R (1985) Learning in honeybees in an ecological and behavioral context. In: Experimental behavioral ecology (Holldobler B, Lindauer M, eds), pp 55-74. Stuttgart: Fish.

Menzel R (1990) Learning, memory, and "cognition" in honey bees. In: Neurobiology of comparative cognition (Kesner RP, Otten DS, eds), pp 237-292. Hillsdale, NJ: Erlbaum.

Menzel R, Bitterman ME (1983) Learning by honeybees in an unnatural situation. In: Neuroethology and behavioral physiology (Huber F, Markl H, eds), pp 206-215. New York: Springer.

Menzel R, Heyne A, Kinzel C, Gerber B, Fiala A (1999) Pharmacological dissociation between the reinforcing, sensitizing, and response-releasing functions of reward in honeybee classical conditioning. Behav Neurosci 113:744-754.

Menzel R, Manz G, Menzel R, Greggers U (2001) Massed and spaced learning in honeybees: the role of CS, US, the intertrial interval, and the test interval. Learn Mem 8:198-208.

Milner B, Squire LR, Kandel ER (1998) Cognitive neuroscience and the study of memory. Neuron 20:445-468.

Misquitta L, Paterson BM (1999) Targeted disruption of gene function in Drosophila by RNA interference (RNA-I): a role for nautilus in embryonic somatic muscle formation. Proc Natl Acad Sci USA 96:1451-1456.

Mobbs PG (1982) The brain of the honeybee Apis mellifera. I. The connections and spatial organizations of the mushroom bodies. Philos Trans R Soc Lond B Biol Sci 298:309-354.

Montgomery MK, Fire A (1998) Double-stranded RNA as a mediator in sequence-specific genetic silencing and co-suppression. Trends Genet 4:255-258.

Montgomery MK, Xu S, Fire A (1998) RNA as a target double-stranded RNA-mediated genetic interference in Caenorhabditis elegans. Proc Natl Acad Sci USA 95:15502-15507.

Müller U (1997) Neuronal cAMP-dependent protein kinase type II is concentrated in mushroom bodies of Drosophila melanogaster and the honeybee Apis mellifera. J Neurobiol 33:33-44.

Müller U, Hildebrandt H (2002) Nitric oxide/cGMP-mediated protein kinase $\mathrm{A}$ activation in the antennal lobes plays an important role in appetitive reflex habituation in the honeybee. J Neurosci 22:8739-8747.

Nathanson JA, Kantham L, Hunnicutt EJ (1989) Isolation and N-terminal 
amino acid sequence of an octopamine ligand binding protein. FEBS Lett 259:117-120.

Pissonnier T, Fabre-Nys C, Poindron P, Keverne EB (1985) The importance of olfactory bulb noradrenaline for maternal recognition in sheep. Physiol Behav 35:361-364.

Robinson K (1999) Towards a molecular analysis of associative learning in the honeybee, Apis mellifera, via massed conditioning and genetic transformation. Dissertation, The Ohio State University, Columbus, Ohio.

Roeder T, Nathanson JA (1994) Photoaffinity labeling of a neuronal octopamine receptor. J Neurochem 63:1516-1521.

Shipley MT, Ennis M (1996) Functional organization of the olfactory system. J Neurobiol 30:123-176.

Smith BH (1997) An analysis of blocking in binary odorant mixtures: an increase but not a decrease in intensity of reinforcement produces unblocking. Behav Neurosci 11:57-69.

Smith BH, Menzel R (1989) The use of electromyogram recordings to quantify odorant discrimination in the honey bee, Apis mellifera. J Insect Physiol 35:369-375.

Sokal RR, Rohlf FJ (1981) Biometry, Ed 2. New York: Freeman.

Spear NE, Miller JS, Jagielo JA (1990) Animal memory and learning. Annu Rev Psychol 41:169-211.

Spradling AC (1986) P element-mediated transformation. In: Drosophila: a practical approach (Roberts DB, ed), pp 178-197. Oxford: IRL.

Stopfer M, Laurent G (1999) Short term memory in olfactory network dynamics. Nature 402:664-668.

Stopfer M, Bhagavan S, Smith BH, Laurent G (1997) Impaired odour discrimination on desynchronization of odour encoding neural assemblies. Nature 390:70-74.

Strausfeld N (1976) Atlas of an insect brain, p 69. Heidelberg: Springer.
Sugamori KS, Demchyshyn LL, McConkey F, Forte MA, Niznik HB (1995) A primordial dopamine D1-like adenylyl cyclase-linked receptor from Drosophila melanogaster displaying poor affinity for benzazepines. FEBS Lett 362:131-138.

Sullivan RM, Wilson DA, Leon M (1989) Norepinephrine and learninginduced plasticity in infant rat olfactory system. J Neurosci 9:3998-4006.

Sullivan SL, Dryer L (1996) Information processing in mammalian olfactory system. J Neurobiol 30:20-36.

Thompson JD, Higgins DG, Gibson TJ (1994) CLUSTALW: improving the sensitivity of the progressive multiple sequence alignment through sequence weighting, position-specific gap penalties and weight matrix choice. Nucleic Acids Res 11:4673-4680.

Tully T (1998) Towards molecular biology of memory: the light's coming on! Nat Neurosci 1:543-545.

Von Nickisch-Rosenegk E, Krieger J, Kubick S, Laage R, Strobel J, Strotmann J, Breer H (1996) Cloning of biogenic amine receptors from moths (Bombyx mori and Heliothis virescens). Insect Biochem Mol Biol 26:817-827.

Wilson DA, Sullivan RM (1994) Neurobiology of associative learning in the neonate: early olfactory learning. Behav Neural Biol 61:1-18.

Wilson DA, Sullivan RM, Leon M (1985) Odor familiarity alters mitral cell response in the olfactory bulb of neonatal rats. Brain Res 354:314-317.

Yuan Q, Harley CW, McLean JH, Knopfel T (2002) Optical imaging of odor preference memory in the rat olfactory bulb. J Neurophysiol $87: 3156-3159$.

Yuan Q, Harley CW, McLean H (2003) Mitral cell $\beta 1$ and 5-HT $\mathrm{H}_{2 \mathrm{~A}}$ receptor colocalization and cAMP coregulation: a new model of norepinephrineinduced learning in the olfactory bulb. Learn Mem 10:5-15. 